\title{
A CITYGML 3D GEODATABASE FOR BUILDINGS’ ENERGY EFFICIENCY
}

\author{
S. Dalla Costa ${ }^{\mathrm{a}, *}$, E. Roccatello ${ }^{\mathrm{a}}$, M. Rumor ${ }^{\mathrm{a}}$ \\ ${ }^{\mathrm{a}}$ Faculty of Regional Planning, University IUAV of Venice, Cà Tron - Santa Croce 1957, Venice, Italy - \\ silvia.dallacosta@iuav.it
}

\section{Commission IV/8}

KEY WORDS: building energy efficiency, energy balance, CityGML, 3D data model, OGC standard, multi-scale approach

\begin{abstract}
:
This paper illustrates the results of a research focused on the development of a multi-scale geodatabase designed to store the data needed to measure the energy buildings performance of buildings to be used for the planning activities of local administrations. Due to the great complexity of the application domain, the proposed data model has been structured in three main components: the building/heating system, the users, and the environmental/territorial context. Furthermore the characteristics of these components and of their mutual relationships have led to the decision to use geometries in the 3D space. The applications also need a significant semantic content, expandable with customized elements and properties. These peculiarities directed us to select the OGC CityGML standard format as the best choice for the data model. This choice has been tested with positive results.
\end{abstract}

\section{INTRODUCTION}

\subsection{Residential buildings' energy efficiency, an overview}

Energy efficiency measures, along with the development of renewable energy plants, have become priority axes of intervention in European policies and programmes.

In this direction, the biggest saving opportunity is tightly linked to the civil sector which is, with an estimated $40 \%$ of global energy consumption, one of the most considerable causes of energy inefficiency, but at the same time a key area to reduce it and the associated $\mathrm{CO}_{2}$ emissions.

During the last years significant energy efficiency improvements have been gained in the whole Europe thanks to new construction methods, greener household appliances, according to EU Energy Label directive (D’Arrico, 2006), and changes in planning activities at urban scale oriented to sustainability such as the Agenda 21 initiatives. Recently an important step to increase the energy efficiency and the use of renewable sources has been done with the launch of the Covenant of Mayor, the mainstream European movement involving local and regional authorities.

Nevertheless in this process, Italy is running late (see Fig. 1). This misalignment is due to three types of weaknesses:

1. Operational: the delay in the adoption of the legislative framework at national and regional level in energy planning and energy certification of existing buildings.

2. Contextual: the underestimation in the energy plans drawing up of the urban context

3. Structural: the difficulty for the public administrations to regulate a private sector formed by actors that for long time have had no interest to operate in accordance with energy efficiency principles.

Though, according to Enea, the Italian national agency for new technologies, energy and sustainable economic development, one of the principal causes of the national delay is the lack of suitable information to support the decision making processes (Enea 2009).
The statistical approach for the analysis used by the public administrations and institutions engaged in the planning activities often effaces the specific local characteristics and doesn't allow to exactly point out the territorial problems (Pileri, 2002).

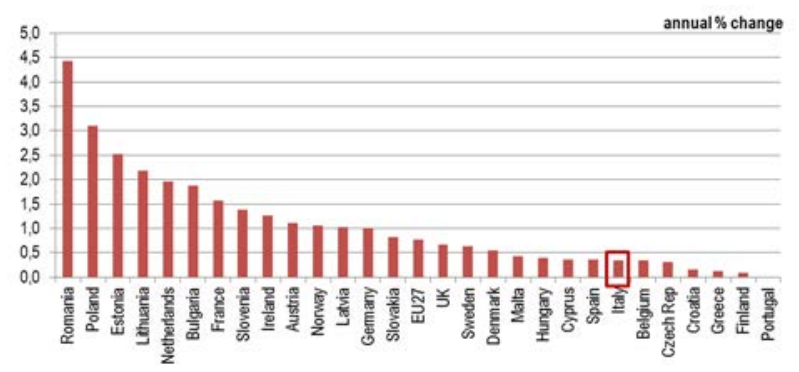

Figure 1. European Energy Efficiency variation 1997-2007 (Mure - Odex source)

\subsection{Research motivations and objectives}

The above-mentioned weaknesses highlight two specific problems that should be solved in order to arrange suitable data and support the energy planning: the grasp of the local context and the comprehension of the relation between energy consumption and users' behaviour, which represents one of the major causes of inefficiency (Dall'O', 2007).

With reference to this framework, the overall objective of the research, conducted by a team of the Faculty of Regional Planning at the University IUAV of Venice, is to support the hypothesis of setting an information system on energy performance of existing buildings through the contribution of a participatory approach and the use of technologies. In particular the system combines public data, organized into a 3D geodatabase, and the stakeholders' involvement.

The research is structured into three main phases. The first one focuses on the problem context and the components of the system - variables and data sources - together with participatory techniques adopted in the proposal. The second phase defines

* Corresponding author. This is useful to know for communication with the appropriate person in cases with more than one author. 
the conceptual and logical data models based on a multi-scale approach- from architecture to urban scale - and three key components, characterizing the building energy performance: the envelope/heating system, the users system and the environmental and territorial system. The last phase of the research proposes a test designed for the construction and validation of the information system.

This paper introduces the design phase, the details about the chosen approach, the 3D conceptual data model and its application in the CityGML format. Finally the test phase on a local administration near Bologna - Comune di Monteveglio, and the achieved results are briefly discussed.

\subsection{Background and references}

The technological evolution in data creation and management over the last decades is also evident in the energy sector: sensors for the analysis and the monitoring of energy efficiency are becoming very common. These instruments (thermal cameras, heat flux meters) could be used to support retrofit interventions or continuous and real time monitoring (smart meters) oriented to increase the citizens level of information and awareness.User-friendly mobile (i.e. BeAware, a European initiative) or web applications such as energy dashboards (i.e. Google Power Meter and Lucid's Building Dashboard) or institutional geoportals to support Sustainable Energy Action Plans are under construction.

Furthermore the Open Geospatial Consortium (OGC) has published in 2007 the White Paper on Sensor Web Enablement (SWE), which proposes seven specifications giving a framework of open standards for exploiting Web-connected sensors and sensor systems of all types (Botts, Percivall, Reed, Davidson, 2007). These specifications complete the OGC standards and services issued to ensure interoperability and data exchange.

Having considered the importance of local context, meteorological variables, geometrical characteristics such as surfaces and volumes that define the heating zones for the calculation of building energy balance, it is inferred that 3D space is the more appropriate data domain for the analysis of energy efficiency.

Even for the management of three-dimensional data a standard approach can be taken into account, through the use of a OGC language like the Keyhole Markup Language (KML) or CityGML. However the application needs a widespread semantic in the model, expandable with customized elements and properties, conveying geometrical as well as alphanumeric data. These peculiarities pointed out OGC CityGML standard format as the best choice for the project.

CityGML is an open data model and XML-based format for the storage and exchange of virtual 3D city models particularly suited to applications that work from architectural to urban scale. Precisely the most significant ongoing researches and projects aim at exploring the integration between 3D Building Information Models and virtual 3D city models (Hagedorn \& Dollner, 2007, Isikdag \& Zlatanova, 2009).

\section{3D GEODATABASE FOR BUILDINGS ENERGY EFFICIENCY}

\subsection{Approach and methodology}

\section{Energy Balance equation}

The information system for measuring the building energy efficiency starts from the assumptions and cultural references above-mentioned and has the geodatabase and the procedures for the acquisition, validation and publication of data and maps as principal components.

The start-up of the proposal has been the analysis and identification of the variables and data source necessary to define the energy performances of existing buildings, which are influenced by the status of the opaque and transparent envelopes, the efficiency of the heating and cooling systems, the local context and the specific users' behaviour.

Therefore the equation of energy balance has been used and specifically the methodologies based on Standard EN 13790: 2008 and EN 15603:2007, applying the asset rating calculation for the evaluation of existent buildings, preliminary to the energy certification.

This calculation method is based on real data related to the building, while standard data referred to local climate and users' activities; this method allows to compare similar buildings and operate assessment of users separately. Afterwards data required by the energy balance equation are completed with other information that describe the heating and cooling systems, the users' habits and their energy consumption, the territorial and environmental context.

It is important to highlight that the energy balance equation represents the exchange of flux and energy between the external environment and the building; this approach can also be extended to build the urban energy balance (Oke, Kalanda, Steyn, 1980, Oke, 1984) or the human energy balance (Franger, 1970).

\section{Information system framework}

The analysis of the variables and the gathered data for the construction of the energy balance integrated with additional information allows to identify the building energy performances and to extend them to the urban scale. In this direction is possible to build the urban energy balance, but mostly to work on multiple levels of detail, from the architectural to urban scale.

This approach has therefore led to define an information system oriented to urban energy performance based on three main components: the building/heating-cooling system, the user system and the environmental and territorial context.

Moving on this direction it is possible to provide the local administrations with data and information necessary to draw up plans, programs, or specific incentives for the civil sector.

\section{$2.23 \mathrm{D}$ conceptual data models}

\section{Data model at architectural scale}

The central element of the information system is the geodatabase that handles both the alpha-numeric and the spatial entities.

The main entity of the geodatabase is the "thermal zone" defined by the UNI EN ISO13790:2008 as a portion of the building acclimatized at a certain temperature by a unique heating, cooling or ventilating device.

To meet the requirement of consistency that every database should have, this definition has been further specified.

In practice, the thermal zone can be represented by an apartment of a building or a single dwelling.

The information required for the construction of energy balance strongly orients the data model towards the three-dimensional representation. Therefore the following spatial entities have been defined: 
- Opaque building element, multipolygon 3D, boundary representation

- $\quad$ Transparent building element, multipolygon 3D, boundary representation

- $\quad$ Context, multipolygon 3D

While the alpha-numeric entities of the geodatabase are:

- $\quad$ Heating system

- Regulation system

- Users

- Renewable source system

- Intervention

The cooling systems were not taken into account, waiting for the release of the technical specifications for the preparation of national energy certificates.

Relations between entities are both alpha-numeric and spatial; for instance a spatial relation is that between the thermal zone and the opaque envelope, which represents the boundary of the thermal zone.

Also the relations between opaque and transparent envelopes are spatial, based on their geometry.

Then the opaque building element, the transparent building element and the thermal zone form a three-dimensional model, including geometry and semantics.

\section{Generalization of the data model for urban scale}

Working at urban scale it was chosen to operate in accordance with the principles of spatial generalization that allow to maintain the minimum entity, i.e. the thermal zone, and at the same time to formulate appropriate combinations and aggregations, coinciding with buildings or urban blocks. Instead of generating a wider entity in the conceptual model above described, during the design phase it has been decided to operate on the definition of the thermal zone, which can change depending on the scale.

The conceptual model at architectural scale represents the schema of greater detail, but when it is impossible to operate at this level, the thermal zone should be defined more broadly and may coincide with a building, a complex of adjacent buildings or with an urban block.
The associated entities, during the generalization phase, will change according to the following rules: the users will be all the users whole, the heating system will be the union of all the heating systems value will be averaged.

Afterwards the definition of "thermal zone collection" has been introduced. This entity could be:

- a building consisting of one or more apartments, with homogeneous thermo-physical characteristics, autonomous heating systems for each dwelling or a unique centralized heating system equipped by meters for every apartment;

- a building consisting of one or more apartments, with homogeneous thermo-physical characteristics, autonomous heating systems for each dwelling a unique centralized heating system without any device of consumption control;

- an aggregation of buildings where the partitions between adjacent apartments, or at least between thermal zones, are considered adiabatic and with homogeneous thermophysical characteristics.

The aggregation procedures depend on the objectives of the stakeholders, usually the public administration, or on the availability of data, i.e. the information already existing or gathered by a specific data collection campaign.

The second E-R schema (Figure 2), for the generalization rules, has these spatial entities:

- Opaque building element, the sum of opaque elements with the same orientation and thermo-physical properties, that define the thermal zone collection; multipolygon 3D, boundary representation;

- Transparent building element, the sum of transparent elements with the same orientation and thermo-physical properties; multipolygon 3D, boundary representation;

- Context, multipolygon 3D.

While the alpha-numeric entities are:

- Heating system: a virtual system, with the same characteristics and performances of the heating systems' sum for a unique thermal zone collection

- Control system: a virtual system, with the same characteristics and performances of the control systems' sum for a unique thermal zone collection

- $\quad$ Users, the sum of presences into a thermal zone collection

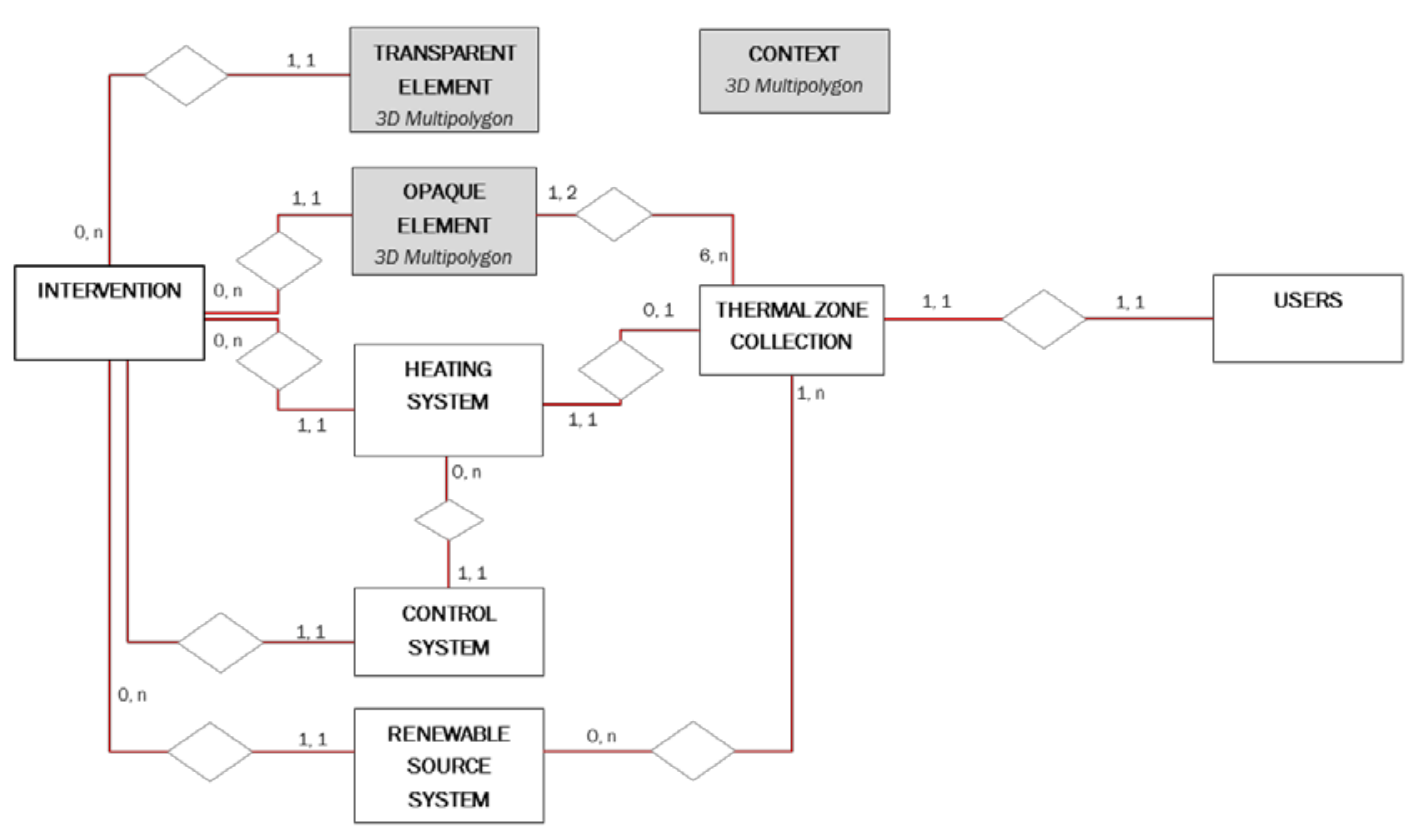

Figure 2: E-R schema for the urban scale 
- $\quad$ Renewable source system: a virtual system, with the same characteristics and performances of the renewable energy systems' sum for a unique thermal zone collection

- Intervention: the sum of retrofit interventions of a unique thermal zone collection

Relations between entities are similar to the E-R schema for the architectural scale. In particular the spatial relations are referred to:

- Thermal zone collection and Opaque building element

Opaque building element and Transparent building element

The entities thermal zone collection, Opaque building element, Transparent building element should define a three-dimensional model.

\subsection{CityGML integration}

In order to ensure a wide range of project applications and to improve reusability, the data storage format choice is very important. OGC specifications restrict instantiable geometry classes to zero, one and two-dimensional geometries, which exists in a bi-dimensional coordinate space.

Assuming we are looking for a standard compliant approach for information system, languages and specifications capable to represent database entities in 3D space must be employed. The Open Geospatial Consortium has issued two tridimensional standard formats: Keyhole Markup Language (KML) and CityGML.

The project application field is tightly linked with semantics and every entity has a large set of custom properties, as we need to deliver not only geometry but also the concerning data. Given these restrictions, the only standard data format suitable for the project aim is CityGML.

\section{CityGML application domain extensions (ADE)}

CityGML has been designed as an application independent format for 3D urban models. Anyway as stated before, additional field-specific properties have to be modeled and delivered within the format.

Specific application domain information and properties can be included directly in a CityGML document instance. This approach works very well when additional information just follows the standard CityGML schema, as there is no need to rework the XML schema thanks to the generic attribute availability.

In this case, as the project data set is quite wide and structured, a more systemic and bounded way to represent custom properties is needed, using an additional XML schema integrated with the CityGML's one.

Application Domain Extensions (ADE) is the CityGML standard mechanism of extension, which allows validationenabled usage of CityGML data format with domain specific extensions.

An ADE XML schema could extend CityGML mainly in two ways:

new classes of features can be defined in ADE namespace, based on CityGML classes, both concrete and abstract. Every new kind of feature must be derived from an existing one and it inherits CityGML parent class' properties and relations. This is the concept behind GML application schema;

- $\quad$ existing feature extensions, in the ADE namespace. New properties could include simple or complex types, allowing further geometries to be added. These extensions could be used to link different features.
CityGML offers a hooking mechanism, which allows XML ADE to bring new properties replacing a specific abstract class. Every item in the CityGML official schema includes a “_GenericApplicationPropertyOf $<$ Feature $>$ ”, which can be repeated if needed.

\section{Designing an energy efficiency CityGML ADE}

Application entities, which are modeled as 3D geometries, are:

- Building

- Thermal Zone

- Opaque building element

- Transparent building element

All building related geometries are 3D MultiPolygon, so they can be easily modeled in a CityGML format instance.

In our representation we are assuming that every Building has a proper geometry for external visualization and that related features are visible only from the interior. Every feature could be enriched with openings if needed, so we have to take in account doors and windows. Concerning this, CityGML level of detail needed for the project is the maximum one, especially considering the required thematic modeling.

CityGML features can be linked to the project entities as follows.

\begin{tabular}{|l|l|}
\hline Geodatabase & CityGML \\
\hline Thermal zone collection & Bldg:Building \\
\hline Thermal zone & Bldg:Room \\
\hline Opaque envelope element & Bldg:BoundarySurface \\
\hline Transparent envelope element & Bldg:Opening \\
\hline
\end{tabular}

Table 1: correlation between the geodatabase entities and CityGML format

The analysis carried out highlights the relation between the Thermal Zone entity in the database and the Room class of CityGML, which could be considered the same. Also, if a Building is considered as a collection of Rooms and Storeys the same link could be made between Thermal Zone Collection and Building. There isn't a tight restriction on the geometry adopted so it is possible to model adjoining storeys and rooms.

The research has delivered a XML ADE schema for CityGML, which enriches the model representation with all attributes defined in the model data, as shown before.

\subsection{Test phase}

Subsequently to the design and implementation of the conceptual, logical and physical data model the information system has been tested on a sample area.

The experiment has been carried out in a local public administration, the town of Monteveglio, engaged on drawing up its energy plan. The choice was justified by the considerable presence in this area of voluntary associations, later involved in the conduction of an energy questionnaire for the users' data collection. The survey has also worked as first mean of citizens' awareness on energy saving.

The test has been organized in three steps: the first one centred on the collection of data belonging to local and regional institutions on buildings, morphology, climate, demography. Moreover the local utilities have made available energy consumption data of the last four years.

All the information have been subsequently elaborated and normalized to be entered in the geodatabase built in PostgreSQL/PostGis. 
The second step has involved a group of volunteers that during the year 2010 have weekly sent to the research team their thermal consumptions, duly compared with the mean temperatures associated to every monitored dwelling, through the application of IDW interpolation method with linear dependence on the altitude.

In addition this group has filled in the energy questionnaire aimed at gathering detailed data concerning the users, that were not available in any data archive. The information can be referred to: heating systems schedule, devices installed for the internal temperature setting, presence of renewable source systems, measures already adopted for energy saving, level of interest on the issue. By this way the energy questionnaire has been tested and adjusted. This phase has allowed to carry on a sensitivity analysis on the variables that influence the energy performance of the envelopes and heating systems.

The analysis is needed to identify the changing of the results as a function of data input, distinguishing the most indicative data from the minor ones, inferable through national or regional statistics.

After the sensitivity analysis, the third step of the test has been developed submitting the energy questionnaire to a neighbourhood, entering the information collected into the geodatabase and eventually working out energy indicators agreed with the public administration of Monteveglio.

\subsection{Results}

Most of the energy indicators require a huge amount of input data. Depending on the indicator's complexity it will be possible to perform calculations directly developing the needed software or to export the data and use them with external energy simulation software.

The collection and elaboration of the data made it possible to build indicators related to the main components of the information system (the envelope/heating system, the users system and the environmental and territorial system) at architectural and urban scale, therefore validating the design of the geodatabase. The results have been submitted as maps and reports to the public administration. The built indicators are listed in table 2.

\begin{tabular}{|l|l|l|}
\hline Indicators & Systems & Scale \\
\hline $\begin{array}{l}\text { Thermal consumption trend } \\
\text { from 2006 to 2009, normalized } \\
\text { to real Degree-Days. }\end{array}$ & $\begin{array}{l}\text { Envelope/ } \\
\text { heating }\end{array}$ & Urban \\
\hline Distribution of the heat losses & $\begin{array}{l}\text { Envelope/ } \\
\text { heating }\end{array}$ & $\begin{array}{l}\text { Architectural } \\
\text { ad urban }\end{array}$ \\
\hline $\begin{array}{l}\text { Domestic hot water production } \\
\text { and heating systems status }\end{array}$ & $\begin{array}{l}\text { Envelope/ } \\
\text { heating }\end{array}$ & Architectural \\
\hline $\begin{array}{l}\text { Equivalent CO emission } \\
\text { calculation }\end{array}$ & $\begin{array}{l}\text { Environmental/ } \\
\text { territorial }\end{array}$ & Urban \\
\hline $\begin{array}{l}\text { Number and territorial } \\
\text { distribution of renewable } \\
\text { energy source systems }\end{array}$ & $\begin{array}{l}\text { Environmental/ } \\
\text { territorial }\end{array}$ & Urban \\
\hline $\begin{array}{l}\text { Presence of the users at home } \\
\text { and control devices for the } \\
\text { heating systems used }\end{array}$ & Users & Architectural \\
\hline $\begin{array}{l}\text { Users beheaviour, perception } \\
\text { of the energy issue, level of } \\
\text { comfort }\end{array}$ & Users & $\begin{array}{l}\text { Architectural } \\
\text { ad urban }\end{array}$ \\
\hline
\end{tabular}

Table 2: Energy indicators developed during the test phase

\subsection{Conclusions}

The most significant outcomes obtained by the research can be summarized as follows:
1. the overcoming at local scale of a statistical approach dealing with performances and energy consumptions of residential buildings to optimize the planning of interventions of rehabilitation at architectural and urban scale;

2. the enhancement of detailed data, which allow to reduce common simplification adopted in the energy calculations;

3. the introduction of 3D geometries for modelling the main entities, increasing the consistency of the representation and simplifying the calculation of the energy balance;

4. the use of a scalable approach, based on CityGML standard format, which makes possible a simultaneous representation of the energy balance at architectural and urban scale.

\section{DISCUSSION}

A 3D approach is fundamental to build an exhaustive information system concerning the energy performances of residential buildings, as they depend on the material quality of envelopes and on the heating systems efficiency as well as on their geometrical properties, i.e. surfaces and volumes, presence of other buildings, territorial morphology, that determine the solar gains or the losses caused by shadows.

The research has allowed to study and to verify the applicability of CityGML format that came out to be the best choice for the representation of three-dimensional urban entities.

In particular CityGML is convenient due to its modularity, obtainable by CityGML Application Domain Extension (ADE). Future developments within the research will be addressed to study the interoperability and in particular to carry out in-depth studies on 3D spatial operators and web services for the publication and exchange of 3D data.

\subsection{Bibliography}

Botts, M. \&Percivall, G. \& Reed, C. \& Davidson, J. 2007. OGC® Sensor Web Enablement: Overview And High Level Architecture. Open GeospatialConsortium

Dall'O', G. 2007. Certificazione energetica degli edifici: verso un recepimento coerente con la Direttiva 2002/91/CE. In Cannaviello M. \& Violano A. (Ed) La certificazione energetica degli edifici esistenti: 95-109. FrancoAngeli, Milano.

D’Arrico, E. 2006. L'Enea per il Risparmio Energetico. Energia, Ambiente e Innovazione n.4/06: 6-28.

Directive 2002/91/EC. Energy Performance of Buildings EPBD

Directive 2006/32/EC. On energy end-use efficiency and energy services and repealing Council Directive 93/76/EEC

Enea 2009. Rapporto Energia e Ambiente 2008, Analisi e Scenari. Ente per le Nuove tecnologie, l'Energia e l'Ambiente, Roma.

Franger, P.O. 1970. Thermal Comfort. McGraw-Hill, New York

Hagedorn B.\&Dollner J. (2007). High-level web service for 3D building information visualization and analysis. GIS '07 Proceedings of the 15th annual ACM international symposium on Advances in geographic information systems. ACM New York, NY, USA @2007 
Isikdag U. \&Zlatanova S. Towards Defining a Framework for Automatic Generation of Buildings in CityGML Using Building Information Models. 3D GEO-INFORMATION SCIENCES Lecture Notes in Geoinformation and Cartography, 2009, Part II, pp. 79-96

Joint Research Center 2010. Guidebook How to develop a Sustainable Energy Action Plan. Publication Office of the European Union.

ODYSSEE-MURE 2009. Energy Efficiency Trends and Policies in the Household \& Tertiary sectors in the EU 27. ADEME Editions, Paris.

Oke, T. R. \&Kalanda, $\quad$ B. $\quad$ D. \&Steyn, $\quad$ D. $\quad$ G. 1980. Parameterization of heat storage in urban areas. Urban Ecology n.5, pp. 45-54.

Oke, T. R. 1984. Towards a prescription for the greater use of climatic principles in settlement planning. Energy and Buildings n. 7, pp. 1-10.

Pileri, P. 2002. Interpretare l'ambiente: gli indicatori di sostenibilità per il governo del territorio. Alinea, Firenze.

Uihlein, A. \& Eder, P. 2009. Towards additional policies to improve the environmental performance of buildings. JRC Scientific and Technical Reports. European Commission Joint Research Centre - Institute for Prospective Technological Studies, Seville. 